\title{
O DIREITO MODERNO SOB A ÓTICA DOS CLÁSSICOS DA SOCIOLOGIA: análises e questionamentos
}

\author{
Amílcar Cardoso Vilaça de Freitas* \\ Elizardo Scarpati Costa*
}

\begin{abstract}
Pretende-se, neste artigo, fazer uma análise acerca do direito moderno a partir das três abordagens clássicas da sociologia - da perspetiva weberiana, durkhemiana e marxiana sobre o campo do direito. Procurar-se-á especificar as diferentes interpretações sociológicas, discutindo-as a partir das relações sociais e políticas estabelecidas entre a sociedade civil, o Estado e as ideologias políticas que concretizam a atual configuração do direito. Assim, como se trata de visões fundadoras, interessa-nos tanto o que elas propuseram quanto o que elas não puderam responder, reclamando continuidades da sociologia jurídica contemporânea, com atenção especial para o caso brasileiro. Portanto, pretende-se demonstrar a abertura paradigmática que a sociologia do direito possui desde sua formação e como o direito, como temática sociológica, está presente desde a fundação da disciplina.

PalAVRAS-CHAvE: Direito. Estado. Sociedade civil. Conflito.
\end{abstract}

O objetivo deste artigo é fazer uma breve explicação do direito moderno socorrendo-se das diferentes abordagens sobre o campo do direito, com enfoque na teoria dos três grandes clássicos da sociologia. Procurar-se-á especificar essas três interpretações sociológicas, discutindo-as a partir das relações sociais e políticas estabelecidas entre a sociedade civil, o Estado e as ideologias políticas que concretizam a atual configuração do direito.

Demonstrar-se-á que as visões dos clássicos, bastante diferenciadas entre si, proporcionam também três formas de enxergar a relação entre direito e sociedade, ou melhor, do direito dentro da sociedade. Uma visão do direito como afirmação de uma vontade de um grupo sobre uma coletividade; uma segunda tendo o direito como emanação de desejos e necessidades de uma socieda-

*Doutorando em Sociologia na Universidade Federal do Rio de Janeiro (PPGSA/UFRJ). Mestre em sociologia e direito pela Universidade Federal Fluminense.

Largo de São Francisco de Paula, 1, sala 420. Cep: 20051-070. Rio de Janeiro, RJ - Brasil. amilcarchicago@yahoo.com.br

* * Doutorando em Ciência Relações de trabalho, Desigualdades Sociais e Sindicalismo. Mestre em Sociologia pela Faculdade de Economia Universidade de Coimbra (FEUC) - Portugal e, mestre em Sociologia pela École en Hautes Etudes en Science Sociales (EHESS) Paris. eliscarpati@hotmail.com de; e, por fim, a visão do direito como legitimador das desigualdades entre as classes sociais. Desse modo, veremos como essas visões continuam atuais e podem ser aplicadas para se entender a realidade contemporânea brasileira.

\section{UMA VISÃO EXTERNA DO DIREITO}

Antes de adentrar propriamente na visão dos clássicos sobre o direito, um breve comentário sobre a sociologia do direito. Operadores do direito, em regra, estão preocupados em definir qual a forma mais justa de se resolverem as questões à luz dos princípios e normas positivas vigentes. Sem ignorar essa necessidade social, o sociólogo do direito se propõe um objetivo diverso: analisar como os fatores externos ao mundo do direito influenciam o processo decisório do direito. Assim, tal objetivo diferencia-se da dogmática jurídica, que trabalha com uma concepção jurídica ideal da teoria pura do direito. ${ }^{1}$ Ou seja, não leva em conside-

${ }^{1}$ Até que ponto o trabalho dos operadores do direito podem e (ou) devem aproveitar-se também do conhecimento pro- 
ração o julgamento da ação individual, embora atribua um forte peso ao campo objetivo, fático e concreto das normas jurídicas existentes. Abandona, assim, o campo do dever-ser. Segundo Max Weber,

[...] a ordem jurídica ideal da teoria do direito não tem diretamente nada a ver com o cosmos das ações [...] efetivas, o objeto da sociologia jurídica, uma vez que ambos se encontram em planos diferentes: a primeira [dogmática jurídica], no plano ideal de vigência pretendida; o segundo, a [Sociologia jurídica] no dos acontecimentos reais (2004, p. 209).

Dessa forma, o direito torna-se preocupação da sociologia como uma atividade social que está em articulação direta com diversos ramos da vida social. E essa preocupação se colocou para a sociologia desde seus clássicos fundadores, no século XIX, que privilegiamos neste artigo.

\section{A SOCIEDADE, O DIREITO E A RACIONALIDADE}

O sociólogo alemão Max Weber contribui decisivamente para a formação de uma sociologia jurídica ou do direito. Segundo Weber,

A lei existe quando há uma probabilidade de que uma ordem seja mantida por um quadro específico de homens que se utilizarão de compulsão física ou psíquica com a intenção de obter conformidade em relação à ordem ou de aplicar sanções à sua violação (1976, p. 61).

Para ele, a assertiva vale para todas as ordens legais, não se restringindo somente às do Estado. Além disso, a estrutura da ordem legal tem influência direta na distribuição de poder dentro de uma comunidade. Em seguida, o autor apresenta sua definição, hoje clássica, de poder:

Em geral, entendemos como 'poder' a possibilidade de um homem ou de um grupo de homens realizarem sua própria vontade numa ação comunal, mesmo contra a resistência de outros que participem da ação (p. 61).
O estudo do autor sobre a temática foi vasto. Em sua obra prima, Economia e sociedade (Weber, 2004), ele estuda alguns tipos de direito em sociedades passadas, como o "[...] direito romano, germânico, francês ou anglo-saxônico, direito judaico, islâmico, hindu, chinês e mesmo o direito consuetudinário polinésio[...]" (Freund, 1987, p. 7), que foram fundamentais para sua consolidação teórica do ponto de vista da concepção de direito moderno e da institucionalização de um conjunto de leis e regras orientadas pelas constituições que surgiram na Europa no século XIX.

Assim, o processo das revoluções liberais iniciadas na Inglaterra e finalizadas na França e nos Estados Unidos foi, segundo Weber (2004), fortemente influenciado pelas teorias gerais dos contratualistas. Dentre eles, destacam-se John Locke, Voltaire, Montesquieu e principalmente Rousseau, que pregavam o fim da tirania e a liberdade de propriedade como princípio básico da igualdade da humanidade.

Em sua análise sobre a sociedade moderna, Weber ressalta que a conquista do comércio intercontinental por parte da burguesia está ligada ao surgimento eà formação de uma nova racionalidade - a mentalidade burguesa, oriunda da ascendência liberal e protestante, inspirada pelo "espírito" subjetivo de acumulação de riqueza, da qual Weber irá tratar em A ética protestante e o espírito do capitalismo (1981).

A sociologia jurídica, na concepção weberiana, visa a estudar os comportamentos dos indivíduos frente ao conjunto de normas jurídicas estabelecidas em uma determinada ordem social legítima. Procura verificar qual o grau de respeito dos indivíduos por essas normas jurídicas preestabelecidas na sociedade. Segundo Julien Freund (1987, p. 50), um dos principais especialistas nos estudos sociológicos de Weber, a sociologia jurídica weberiana

[...] tem por objeto compreender o comportamento significativo dos membros de um grupamento quanto às leis em vigor e determinar o sentido da crença em sua validade ou na ordem que elas estabeleceram. Procura, pois, apreender até que ponto as re- 
gras de direito são observadas, e como os indivíduos orientam de acordo com elas a sua conduta.

Sendo assim, a questão da norma jurídica em Weber leva em conta a atuação individual e coletiva sobre a legalidade de determinada ordem jurídica. Nesse sentido, a aceitação ou não dessa norma não impede sua transgressão. Ou seja, a sociologia jurídica de Weber trabalha com as normas no plano das ações humanas com base no sistema jurídico vigente e leva em conta os aspetos subjetivos das regras sociais estabelecidas levando em consideração os agrupamentos sociais.

É justamente nesse ponto que ocorre $\mathrm{o}$ afastamento da sociologia jurídica weberiana em relação ao dogmatismo jurídico. O corte epistemológico do princípio da ação social constitui a base da sociologia compreensiva de Weber - que busca compreender e interpretar o sentido, o desenvolvimento, e os efeitos da conduta de um ou de mais indivíduos com relação a outros. Assim, para ele:

A sociologia é a ciência que pretende entender, interpretando-a, a ação social para, dessa maneira, explicá-la causalmente em seu desenvolvimento e efeitos, observando suas regularidades as quais se expressam na forma de usos, costumes ou situações de interesses (Weber, 2004, p. 5).

Além disso, a sociologia jurídica weberiana trabalha com uma perspetiva do ponto de vista da probabilidade da efetivação positiva ou negativa dos indivíduos frente ao direito. Uma dogmática jurídica clássica não utilizaria esse método para analisar as probabilidades objetivas e subjetivas do sistema jurídico com relação aos agentes sociais, que são portadores de vontades próprias, arraigadas por costumes e tradições que, muitas vezes, são colocados em xeque pelos sentidos que os indivíduos atribuem às suas ações sociais.

\section{O Estado moderno e o direito}

Com o aprofundamento das relações sociais estabelecidas na sociedade civil, há uma crescente demanda por organização dos vários setores da vida pública e privada. Portanto, a racionalidade burocrática foi o caminho encontrado pelos juristas e pelos políticos para manterem uma dominação legal do todo social. Estabelecem-se, assim, as possibilidades de uso do poder estatal republicano nas sociedades ocidentais. Portanto, no ponto alto dessas considerações, Weber analisa a burocracia como o maior sinônimo de dominação legal das sociedades modernas.

Por outro lado, antes de prosseguir, vale ressaltar a perspetiva weberiana de dominação. Em oposição ao poder, a égide da dominação é

[...] um estado de coisas pelo qual uma vontade manifesta (mandato) do dominador ou dos dominadores influi sobre os atos de outros (do dominado ou dos dominados), de tal modo que, em um grau socialmente relevante, estes atos têm lugar como se os dominados tivessem adotado por si mesmos e como máxima de sua ação o conteúdo do mandato (obediência) (Weber, 2004, p. 96).

Assim, se o poder se coloca como a imposição de uma vontade em meio à resistência, a dominação aparece como aceitação da vontade do dominante, como se ela espontaneamente brotasse do dominado também. Em qualquer sociedade historicamente localizada, sempre existiram algumas formas de dominação por parte das instituições sociais incumbidas de manter uma determinada ordem estabelecida. Assim, o direito parte do corpo burocrático do Estado e, na teoria, não pode estar desconectado das mudanças que se passam na vida social. É preciso existir uma razão de "ser", uma aceitação social por parte da sociedade em relação às novas leis promulgadas, ou, no mínimo, um reconhecimento por parte dos setores geradores de opinião, como a mídia, por exemplo.

Na tentativa de criar um modelo explicativo, Weber constituiu tipos ideais. A idealidade dos tipos remete ao fato de que eles são uma criação do pesquisador, a fim de poder facilitar a explicação, isolando os tipos entre si. Permite, assim, também testar as hipóteses sobre o funcionamento de cada tipo através da pesquisa empírica. Idealmente, separa as formas de dominação legítimas em três tipos puros, a tradicional, a carismática e a forma 
que se destacaria atualmente, intitulada por Weber como racional-legal. Logo,

Há o domínio da legalidade, em virtude da fé na validade do estatuto legal e da competência funcional, baseada em regras racionalmente criadas. Nesse caso, espera-se o cumprimento das obrigações estatutárias. É o domínio exercido pelo moderno servidor do Estado e por todos os portadores do poder que, sob este aspecto, a ele se assemelham (1979, p. 99).

É preciso ressaltar que esse tipo de dominação apareceria, na prática, possivelmente conjugado com traços dos demais tipos, já que Weber não dá como excluídos da modernidade traços de tradicionalismo ou a influência de carismas pessoais. Porém é o tipo ideal de dominação legal que ele verifica estar se consolidando como principal. Esse tipo torna previsível a ação dos indivíduos e estável do ponto de vista da ação de determinado indivíduo frente às normatizações jurídicas e administrativas. Nesse sentido, o sistema de leis aplica-se a todas as classes sociais, trabalhando-se dentro de uma perspectiva de que o sistema jurídico funcione com igualdade para todos os membros da sociedade.

Na civilização ocidental, os diversos aspectos do Estado moderno só aparecem gradualmente, quando a legitimidade passou a ser atribuída ao conjunto de normas que governava o exercício da autoridade. Esse sistema de normas que constitui a ordem jurídica e a comunidade política é considerado seu único criador normal (Bendix, 1986, p. 324)

Em que medida esse tipo ideal reflete a prática e se sobrepõe aos demais tipos de dominação legítima é uma questão a ser verificada empiricamente. Outra questão que permanece em aberto, já que o próprio Weber oscila entre as diferentes definições, seria se a esfera legal é o exercício de poder (aplicação de uma vontade contra possíveis resistências), ou a consolidação de uma dominação (aceitação legítima de um mandato), conforme é apresentado no tipo puro de dominação racional-legal.

Por um lado, em sua definição de partidos, por exemplo, Weber os coloca diretamente vinculados ao poder. Sendo assim, “[...] sua ação é ori- entada no sentido da aquisição de 'poder' social, o que quer dizer no sentido de influenciar uma ação comunal a despeito de qual seja o seu conteúdo. [...] as ações de partido sempre se dirigem para um objetivo pelo qual se luta de uma forma planejada” (Weber, 1976, p.81).

Por outro lado, a definição weberiana de burocracia aponta para uma racionalidade e uma impessoalidade presentes na construção da burocracia legal. Nesse sentido,

[...] todo direito consiste, essencialmente, num sistema integrado de normas abstratas. Ademais, a administração de lei consiste na aplicação dessas normas a casos particulares. O processo administrativo é a busca racional dos interesses [...] dentro dos limites estabelecidos pelos preceitos legais [...] (Weber, 1966, p. 16).

E ainda, “[...] que toda norma legal dada pode ser estabelecida por acordo, ou imposição [...]” (Weber, 1966, p. 16). Assim, o que não fica claro é como se diferenciam situações em que a norma é imposta de situações em que ela é acordada. ${ }^{2}$ Essa questão pode parecer, num primeiro momento, teórica e abstrata em excesso, mas ela é central para o entendimento da visão do direito pela ótica weberiana. Em termos práticos: o direito - mais especificamente, as leis e a jurisprudência - surge, nas sociedades modernas, como preceitos e decisões racionais e legítimas (não obstante, nesse sentido, sua desobediência eventual), ou como imposições de poder?

Dificilmente a resposta a essa problemática será plena para qualquer dos extremos. E, provavelmente, sem abandonar a ótica weberiana, a questão só será respondida empiricamente. Ou seja, depende de como os indivíduos percebem o direito, o que tende a ser uma construção complexa, que dificilmente pode ser medida no campo abstrato. Se assim for, essa análise escapa dos propósitos deste artigo. Contudo, ressaltamos a importância da questão: a forma como se percebe o direito influi diretamente em como os indivíduos agem diante dele, o que, para um referencial de sociolo-

Essa problemática já fora levantada por Alvin W. Gouldner (1966) 
gia compreensiva, como é a de Weber, não é nem um pouco desprezível.

\section{SOCIEDADE, DIREITO, RELAÇÕES HARMONI- OSAS E A MORAL SOCIAL}

Contemporâneo de Weber, Émile Durkheim definia o objeto da sociologia de maneira mais voltada para a coletividade do que Weber. Assim, definiu a sociologia como a ciência "das instituições, da sua gênese e do seu funcionamento", ou seja, "de toda crença, todo o comportamento instituído pela coletividade" (2001, p.26). Seu objeto próprio, para ele, são os fatos sociais - “[...] toda maneira de fazer, fixada ou não, suscetível de exercer sobre o indivíduo uma coerção exterior; ou então ainda, que é geral no âmbito de uma dada sociedade, tendo, ao mesmo tempo, uma existência própria, independente das suas manifestações individuais" (Durkheim, 2001, p.40).

O direito seria, portanto, uma das expressões desses fatos sociais. Segundo ele, “[...] além dos atos individuais que suscitam, os hábitos coletivos exprimem-se sob formas definidas, regras jurídicas, morais, ditados populares, fatos de estrutura social, etc.”. E prossegue afirmando que “[...] uma regra do direito é o que é, e não há duas maneiras de percebê-la. [...] estas práticas não são senão vida social consolidada [...]" (Durkheim, 2001, p.65, grifos nossos). A conexão entre vida social e direito, para Durkheim, é inequívoca, como se o direito germinasse espontaneamente da vida social.

A centralidade do direito, em sua obra, está presente na sua teoria da consciência coletiva e das solidariedades sociais (Durkhiem, 1995). Assim, para Durkheim, o tipo de direito que rege uma sociedade varia conforme o tipo de solidariedade (mecânica ou orgânica) que constitui a organização social. Em sociedades nas quais a solidariedade é mecânica, o tipo de direito praticado é o repressivo. E, naquelas em que a solidariedade é orgânica, característica do direito moderno, o tipo de direito é o restitutivo.

Mas o que significaria cada uma dessas cons- truções? Para Durkheim, as sociedades primitivas (de solidariedade mecânica) teriam um espírito coletivo forte e pouco espaço para a individualidade. Nesse sentido, o direito repressivo representa a expressão da consciência coletiva forte, em que os indivíduos são ligados a laços sociais rígidos desde seu nascimento. Desse modo, qualquer quebra de regra pede uma expiação, uma atribuição de culpa. Sociedades mais "simples", nesse sentido, seriam também mais punitivas.

Já o direito restitutivo acompanha o desenvolvimento da consciência individual dos cidadãos e se desenvolve à medida que retrocede a consciência coletiva. Nesse sentido, as sociedades modernas capitalistas tornaram-se mais complexas na organização social, após a primeira revolução industrial, com o aumento da divisão do trabalho social, adotando, portanto, uma solidariedade orgânica, ou seja, que mantém o funcionamento social contemplando as diferentes funções que cada parte do corpo social exerce.

Assim, o direito, como fato social, passa a cumprir um papel ímpar no acompanhamento do desenvolvimento social em todas as esferas da vida pública e privada, sendo marcado por características que são sui generis, como fator fundamental para o remodelamento das estruturas sociais, que são dotadas de "vontades próprias”, e para a manutenção da ordem vigente.

Observe-se que, dessa forma, o direito das sociedades modernas permite o desenvolvimento individual, e esse fator não é desprezível para a história recente do Ocidente. As progressivas declarações de Direitos Humanos, ou o predomínio dos princípios constitucionais na dogmática jurídica na atualidade, apontam para um novo respeito jurídico aos direitos individuais, e, podemos dizer, em conformidade com Durkheim. Esse processo não começou no século XX, mas é o reflexo da forma como o direito passa a ser pensando nas sociedades modernas.

Retomaremos esse ponto posteriormente. Neste momento, é mister frisar que, para Durkheim, o direito não só permite distinguir os dois tipos fundamentais de solidariedade social, mas tam- 
bém, garante a perpetuação no que se refere à evolução das sociedades - os valores morais, os costumes e os hábitos da vida cotidiana continuam "vivos" mesmo com a morte dos indivíduos, e se perpetuem com o nascimento e a educação dos próximos cidadãos.

Durkheim, inclusive, aponta posteriormente que o crime é um fenômeno normal nas sociedades, desde que não ultrapasse certas taxas. Para o autor francês, somente um determinado nível de transgressão poderia permitir que as regras fossem devidamente avaliadas, reforçando a consciência coletiva na afirmação dessas regras, ou até mesmo, eventualmente, fazendo perceber que a regra jurídica não mais condiz com o estágio da consciência coletiva, e precisa, portanto, ser reformulada (2001, p.82).

Retornando à perspectiva evolutiva de Durkheim, para ele, é com a passagem do direito repressivo para o direito restitutivo que se percebe e se marca a transformação das sociedades "simples" nas complexas. Revela, assim, o nível de transição (progresso social) de um tipo de sociedade arcaica para um tipo de sociedade na qual a divisão do trabalhoé mais complexa. Por consequência, a solidariedade orgânica substitui a solidariedade mecânica.

Com o advento da solidariedade orgânica, surgem novas demandas na sociedade. A estruturação do direito e as características da burocracia, arquitetadas na figura do Estado, são fatores que podem ser verificados na vida moral da sociedade. A coesão, a moralidade e a anomia (ausência ou pouca força das normas) social serão fatores a serem observados no âmbito do direito e da justiça que caracterizam essa nova forma de organização.

\section{O Estado Moral e o direito}

No ensaio Lições de Sociologia: a moral, O direito e o Estado, Durkheim (1983) procura definir, de forma implícita e explícita, o surgimento do direito como regulamentador das ações individuais e coletivas através da evolução do contrato social. Nesse ensaio, ele parte da noção de propriedade, pois ela se tornou juridicamente indispen- sável para a sobrevivência da sociedade. A propriedade transformou-se no maior sinônimo de harmonia social, por um lado, fortalecendo a solidariedade orgânica em detrimento da divisão do trabalho social. Por outro lado, ele acreditava que o maior agente da anomia social era a ausência de regras jurídicas mais claras - a legislação precisava ser mais concisa e incisiva com relação à herança da propriedade, tendo em vista o contexto de guerras que a Europa vivia naquele momento.

Assim, os fatos morais e jurídicos ${ }^{3}$ consistem em um conjunto de regras de condutas sancionadas, e é nesse sentido que caminha sua explicação para a formação do campo do direito. A sanção, para ele, é uma construção coletiva e representa a exteriorização do bem comum. Por exemplo, se um homem resolve praticar um roubo, ele será sancionado pelo seu ato conforme um conjunto de regras preestabelecidas. O roubo é punido, e essa pena é a sanção que varia de acordo com o tipo de sociedade. Isso ocorre porque, nessa sociedade, o roubo é imoral e detestável socialmente. Se esse fenômeno ocorresse em outra sociedade, onde a noção de propriedade não fosse vista moralmente como central, a sanção não seria manifestada como uma restituição dos valores morais e jurídicos que regem essa sociedade.

As regras da moral individual têm por função, com efeito, fixar na consciência do indivíduo as bases fundamentais e gerais de toda a moral; é nessas bases que descansa todo o resto. As regras, ao contrário, que determinam os deveres dos homens uns para com os outros, pelo simples fato de serem homens são a parte culminante da ética, o ponto mais elevado, a sublimação do resto (Durkheim, 1983, p.109).

Em suma, as regras morais possuem uma autoridade que implica a noção de dever. Essa noção leva a sociedade a um equilíbrio e à sua ostentação como instituição sólida.

\footnotetext{
Para Durkheim (1983, p.60), "Moral [...] é tudo o que fonte de solidariedade, tudo o que força o indivíduo a contar com o seu próximo, a regular seus movimentos com base em outra coisa que não os impulsos de seu egoísmo, e a moralidade é tanto mais sólida quanto mais numerosos e fortes são os laços".
} 
Somente uma sociedade constituída goza da supremacia moral e material indispensável para fazer a lei para os indivíduos; pois só a personalidade moral que esteja acima das personalidades particulares é que forma a coletividade. Somente assim ela tem a continuidade e mesmo a perenidade necessária para manter a regra acima das relações efêmeras que a encarnam diariamente (Durkheim, 1995, p.10).

Nesse ensaio, podemos notar que, apesar de se tornar mais restitutivo de forma geral, o respeito aos direitos individuais ganha maior predominância em certos aspectos da vida moral e social. Os crimes contra a propriedade são os que, com o avanço da modernidade, mais geram encarcerados (Rusche; Kirchheimer, 2004), uma vez que ele está presente de maneira central na moral social moderna.

Assim, o regime de uma sociedade baseada principalmente na restituição e no direito individual deve, no entanto, apresentar novas fórmulas de direito e de contrato social. Grande parte da discussão sobre o direito que Durkheim propõe é bem abrangente e também aponta para uma abordagem sobre o tipo de contrato social. Nesse sentido, ele irá mostrar a dificuldade de as sociedades modernas estabelecerem uma linha evolutiva do contrato, que era, antes do século XIX, puramente estatutário, ${ }^{4}$ em fusão com o contrato moral.

Segundo Durkheim, a concepção de laço social que une os indivíduos na mesma comunidade teria sido, ou deveria ter sido, contratado, como entende Rousseau. Logicamente, a noção de contrato parece aqui clara em si mesma, pois é regra geral que as novas instituições sociais modelaram-se pelas antigas para desenvolver livremente a sua própria natureza. Assim, para Durkheim (1983, p.130-132), os contratos sociais são feitos de dois elementos centrais: o núcleo verbal e a fórmula; depois, os ritos materiais.

O contrato consensual é, em última análise, como que o remate, o ponto no qual vieram convergir, desenvolvendo-se o contrato real de um lado, e o contrato verbal solene de outro. No contrato real há tradição de uma coisa, e é essa tradição que engendra a obrigação; por haver recebido tal ob${ }^{4}$ Aqui a referência é a partir da formação do Estado-Nação
no século XV. jeto cedido por vós, torno-me vosso devedor. No contrato solene, não há prestação efetuada; tudo se passa em palavras, acompanhadas, geralmente, de alguns gestos rituais.

O regime do contrato social real e do contrato solene corresponde a um estágio da evolução social em que o direito dos indivíduos ainda não era senão fracamente respeitado. O contrato consensual constitui uma revolução jurídica. Assim, esse tipo de contrato, feito pela declaração das vontades individuais, teve como efeito transformar as antigas instituições sociais em um mesmo agregado de valores morais e políticos. Portanto, o contrato é sancionado, é bilateral, é de boa fé. Porém o princípio no qual repousa a instituição, assim renovada, contém, em si, o germe de todo um desenvolvimento do qual nos cumpre, agora, narrar as sequências, as causas, e determinar qual é a orientação social. Ele avança ainda para outro tipo de contrato, o equitativo.

Assim, a adequação dos contratos sociais em relação à forma de que a sociedade necessita, em meio ao surgimento de novas demandas da vida social, é notada por Durkheim (1983) como o reordenamento social da capacidade de mudança do gerenciamento social. Nesse caso, essa adequação atinge diretamente as novas configurações do direito na vida moral e social, uma vez que a edição de novos contratos sociais, ao longo do desenvolvimento da sociedade, é constante e aparentemente indispensável para o curso linear que segue o progresso social.

Ora, essa união com algo que supera o indivíduo, essa subordinação dos interesses particulares ao interesse geral é a própria fonte de toda atividade moral. Se sentimento se precisa e se determina, quando, aplicando-se às circunstâncias mais ordinárias e mais importantes da vida, se traduz em fórmulas definidas, temos um corpo de regras morais prestes a se constituir (Durkheim, 1995, p.17).

As mudanças da legislação e da doutrina jurídica vêm aparentemente confirmando a colocação de Durkheim quanto ao maior respeito aos direitos individuais, à autodeterminação dos cidadãos e às novas formas de contrato. Porém, na rela- 
ção com direito penal (ou repressivo, na terminologia durkheimiana), verifica-se um problema: a vontade punitiva, nos países modernos, não diminuiu. A necessidade por expiação não desaparece; pelo contrário, nas últimas décadas, observa-se um aumento no desejo por pena (Bauman, 2000; Wacquant, 2007). Contraditoriamente ao colocado por Durkheim, mesmo sem uma consciência coletiva forte, mesmo com processos de individualização bastante avançados, a onda punitiva não diminui, e a sociedade pede do "mundo jurídico" respostas para punir mais gente, de forma mais imediata e por mais tempo.

Provavelmente, a resposta, dentro da teoria de Durkheim, aponte para algum tipo de anomia, de ausência de regramento social que permite essa situação. Obviamente, como apontamos antes, a proteção do direito à propriedade trazida por Durkheim é um fator a ser considerado nessa resposta. Mas ele nos parece, se nos é permitida a metáfora, "a ponta do iceberg” de qual seria o núcleo da consciência coletiva (afinal, a consciência coletiva diminui, mas não desaparece) presente contemporaneamente, que ainda permite ao direito punitivo manter-se com tamanho esplendor. Mas todo esse movimento punitivo mantém-se de modo condizente com as condições contratuais da vida coletiva que Durkheim aponta, conservando a propriedade através da moral contratual.

\section{SOCIEDADE, DIREITOE RELAÇÕES CONFLITUOSAS}

Na obra de Karl Marx, em alguns dos seus escritos sobre o Estado, sobre as relações de produção e de reprodução da vida social, podemos encontrar elementos básicos de uma sociologia jurídica. Assim como para Weber e Durkheim, ele vê o direito como uma instituição ímpar do corpo burocrático do Estado. Diferentemente, no entanto, Marx aponta a estruturação produtiva como fator central da realidade social.

A institucionalização das normas e das regras sociais que emergem numa determinada conjuntura histórica é fruto da intervenção humana na realidade social. Essas transformações estão sempre ligadas com a estrutura de classes sociais que determina as sociedades. Por vezes, em períodos de inquietação social, nos quais a luta de classes está colocada em questão, as classes sociais tentam impor sua vontade dentro desse contexto histórico. Ademais, desse processo conflituoso surge o direito como instituição social responsável por manter, estabelecer e propagar a nova ordem social de uma classe social hegemônica. Esse novo direito, assim como o Estado moderno, será analisado por Marx como forma de consciências sociais ou formas ideológicas - ligadas ao conjunto de ideias dominantes na sociedade -, a chamada ideologia.

Nesse sentido, a formação das classes sociais dentro de uma determinada sociedade vai depender diretamente das posições que cada grupo de pessoas ocupa no sistema produtivo. Para Marx, ao longo da história e dos diferentes modos de produção, constituíram-se, em regra, duas grandes classes principais: uma dominante, exploradora, e outra dominada, explorada, como donos de escravos e escravos, servos e senhores feudais e, finalmente, a burguesia e o proletariado. A ideologia, em uma sociedade de classes como a capitalista, vai representar o modelo idealizado de Estado, bem como o estabelecimento das regras de funcionamento desse Estado. Será, portanto, a expressão máxima das relações sociais do ponto de vista da classe dominante.

Para Marx, são os homens que produzem suas representações sociais, suas ideias, etc. Mas são os homens reais, atuantes, tal como foram condicionados por um determinado desenvolvimento das suas forças produtivas e do modo de relações que lhes correspondem, incluindo até as formas mais amplas que elas possam tomar.

Não tem história, não tem desenvolvimento; serão, antes, os homens que, desenvolvendo a sua produção material e as suas relações materiais, transformam, com esta realidade que lhes é própria, o seu pensamento e os produtos deste pensamento. Não é a consciência que determina a vida, mas sim a vida que determina a consciência (Marx; Engels, 2002, p. 25). 
As ideias, assim, não emergem do nada, pois emergem da vida cotidiana, baseadas no sistema produtivo. Essa distinção levou Marx a constituir uma divisão clássica entre infraestrutura (forças produtivas e relações sociais de produção) e superestrutura (relações ideológicas, políticas, jurídicas). Dentro do conceito de superestrutura ou supraestrutura, Marx vai trabalhar os tipos de consciência coletiva que se polarizam nas sociedades modernas. Em suma, as formações do direito e do Estado moderno estão ligadas ao modo de produção capitalista, tendo o processo de industrialização contribuído decisivamente para essa formação - a chamada infraestrutura - que é o conjunto das forças produtivas e das relações sociais de produção no qual uma sociedade forma sua arquitetura produtiva e que, por sua vez, segundo Marx, constitui o fundamento sobre o qual se constituem as instituições políticas, sociais e jurídicas, e que, em última instância, vai determinar a forma de organização social e a posição das classes sociais.

Portanto, os indivíduos das classes exploradas podem assumir a posição ideológica oferecida pela classe dominante, ou podem compreender sua situação de classe e passarem a combater a ideologia vigente. Dessa possível conscientização, Marx levanta a ideia de classe em si e classe para si:

[...] as classes em si, conjunto de membros de uma sociedade que são identificados por compartilhar determinadas condições objetivas, ou mesma situação no que se refere à propriedade dos meios de produção, das classes para si, classes que se organizam politicamente para defesa consciente de seus interesses, cuja identidade é construída também do ponto de vista subjetivo (Quintaneiro, et al., 2002, p.43-44).

Assim, o direito não irá ser justo para todos os cidadãos sob a autoridade do mesmo Estado. Mas, justamente devido ao processo ideológico que permeia as diversas instituições sociais, a ideia dominante é de que a sociedade é homogênea e composta por um mesmo corpo social de interesses. A luta pela hegemonia social na esfera política e jurídica é constante desde o surgimento das sociedades capitalistas:
[...] mantiveram uma luta constante, velada umas vezes e noutras franca e aberta; luta que terminou sempre com a transformação revolucionária de toda a sociedade ou pelo colapso das classes em luta” (Marx; Engels, 1997, p.26).

Nesse sentido, os primeiros artigos jurídicos de Marx estão presentes de maneira explícita no período da sua vida conhecido como o jovem Marx, pois, ainda nesse período, ele era marcado pela influência da filosofia hegeliana e kantiana. Por outro lado, a crítica da filosofia alemã do direito e do Estado, que teve a mais lógica, profunda e completa expressão em Hegel, surge, ao mesmo tempo, como análise crítica do Estado moderno e da realidade a ele associada e como negação definitiva de todas as anteriores formas de consciência na jurisprudência e na política alemã, cuja expressão mais distinta e mais elevada, no âmbito da ciência, é precisamente a filosofia especulativa do Direito (Marx, 1989b, p. 52).

Contudo, ao longo de sua produção, Marx rompe definitivamente com a filosofia do direito tanto de Hegel quanto de Kant, construindo uma análise inovadora da sociedade. Para prosseguirmos na análise da teoria marxiana a respeito do direito, é fundamental uma discussão mais aprofundada do conceito de ideologia.

\section{A ideologia jurídica em Marx}

A ideologia tem um papel fundamental na análise filosófica e científica de Marx e Engels. O conceito de ideologia como maneira enviesada ou enganosa de observar o mundo, é central na construção do materialismo histórico; “[...] assim como o Estado é o Estado da classe dominante, as ideias da classe dominante são ideias dominantes em cada época” (Marx; Engels, 2002, p.32).

Na nossa sociedade, devido à ordem jurídica, a sensação que temos é de que os cidadãos são iguais perante a lei, com a ideia de que o pressuposto jurídico do contrato social beneficia a todas as partes livres. Nesse sentido, o direito cria ilusões de que há uma igualdade jurídica entre todos os cidadãos. 
Não se trata de má-fé, assinalaram Marx e Engels, uma vez que a má-fé pressupõe uma distorção consciente e voluntária; a ideologia é cegueira parcial da inteligência entorpecida pela propaganda dos que a forjaram. O "discurso competente", em que a ciência se corrompe a fim de servir à dominação, mantém ligação inextricável com o discurso conveniente, mediante o qual as classes privilegiadas substituem a realidade pela imagem que lhes é mais favorável, e tratam de impô-la aos demais, com todos os recursos de que dispõem (órgãos de comunicação de massa, ensino, instrumentos especiais de controle social de que participam e, claro, como forma destacada, as próprias leis) (Lyra, 2005, p. 17-18).

Sendo assim, o Estado, para Marx, é uma instituição de poder que tem por função assegurar os conflitos entres as classes sociais no âmbito de uma ordem convencionada. O direito, por sua vez, é fruto das relações sociais na sociedade capitalista e institucionalizada na esfera político-jurídica, e é sempre conduzido, na análise marxiana, como um paralogismo que designa apenas as normas da classe dominante: “[...] o Estado se impõe na condição de comunidade dos homens. Mas é uma comunidade ilusória, pois o Estado, por baixo das aparências ideológicas de que, necessariamente, se reveste está sempre vinculado à classe dominante e constitui seu órgão de dominação" (Marx; Engels, 2002, p. 30-31).

Para Marx, mesmo quando o Estado consegue se desvencilhar de certos aspectos da ideologia dominante, essa desvinculação não é senão ilusória. Assim, o Estado elimina, à sua maneira, as distinções estabelecidas por nascimento, posição social, educação e profissão, ao decretar que o nascimento, a posição social, a educação e a profissão são distinções não políticas; ao proclamar, sem olhar tais distinções, que todo o membro do povo é igual parceiro na soberania popular e ao tratar do ponto de vista do Estado todos os elementos que compõem a vida real da nação. No entanto, o Estado permite que a propriedade privada, a educação e a profissão atuem à sua maneira, isto é, como propriedade privada, como educação e profissão, e mani- festem a sua natureza particular (Marx, 1989a, p.12).

Nesse marco, o mero desligamento do Estado da religião não impede que, na vida cotidiana, o preconceito religioso continue existindo, bem como a proibição da discriminação racial não põe fim ao racismo, como o fim do voto censitário não leva a termo a desigualdade entre as classes sociais. Da mesma forma, o reconhecimento da igualdade formal pela lei não impede que "[...] todos os pressupostos da vida egoísta [continuem] a existir na sociedade civil, fora da esfera política, como propriedade da sociedade civil.” (Marx, 1989a, p.12-13).

A universalidade e a igualdade apresentadas pelo Estado são, para Marx, ilusórias. Ao passo que como seres reais, os Homens experimentam suas desigualdades sociais. Marx chama de emancipação política o fato de a religião, a propriedade privada, o nascimento, a educação, etc. ficarem relegados à esfera privada, de forma que, para o Estado, todos possam ser considerados igualmente cidadãos antes de serem considerados por sua religião, propriedade, educação, etc. Mas a emancipação política apresenta limites. A superação das desigualdades (religiosas, de classe, de nascimento...) só é possível transformando as condições objetivas de vida permanentemente (Marx, 1989a, p.16).

Marx aprofunda sua reflexão analisando artigos das constituições estadunidenses - tanto da União, quanto de alguns estados - e da Declaração Universal dos Direitos do Homem e do Cidadão francesa. Assim, para o autor, os direitos fundamentais burgueses são direitos do isolamento e da união:

[...] a liberdade como direito do homem não se funda nas relações entre homem e homem, mas antes na separação do homem a respeito do homem.É o direito de tal separação, o direito do indivíduo circunscrito, fechado em si mesmo. [...] O direito humano da propriedade privada é, portanto, o direito de fruir da própria fortuna e de dela dispor como se quiser, sem atenção aos outros homens, independentemente da sociedade (1989a, p.24).

E soma a esses direitos já colocados o de segurança, apresentado por ele como o direito de polícia, da preservação da vida e da propriedade, 
ou seja, como garantia do egoísmo. O outro não surge, portanto, para afirmar os direitos, mas para limitá-los. Os direitos burgueses surgem como direitos egoístas (liberdade, propriedade, segurança), e a igualdade formal serviria apenas para reforçar que cada um pode usufruir de sua liberdade e de sua propriedade (se a tiver) da maneira que bem entender e em segurança.

Assim, a emancipação humana só será plena quando o homem real e individual tiver em si o cidadão abstrato; quando, como homem individual, na sua vida empírica, no trabalho e nas suas relações individuais, se tiver tornado um ser genérico; e quando tiver reconhecido e organizado as suas próprias forças (forces propres) como forças sociais, de maneira a nunca mais separar de si essa força social como força política (Marx, 1989a, p.30).

O que não fica claro é como pensar a diversidade, uma vez que a liberdade foi apontada como um direito egoísta. Como a emancipação humana plena conviverá sem a liberdade, ou seja, como será possível a discordância, o desacordo com a maioria e com a comunidade política, sem haver o individualismo? Em suma, haveria emancipação plena sem levar em conta e dar aval às idiossincrasias individuais e culturais dos diferentes povos? Em outros termos, se há razão para acreditar, dentro da teoria marxista, que o direito das sociedades atuais não é mais do que a expressão das relações injustas e desiguais dessa sociedade e permite o isolamento do indivíduo real da vida cidadã, como seria o direito em uma sociedade de emancipação social plena? E mais: não poderia ser o direito também um instrumento na luta de classes e no desenvolvimento da emancipação humana? Todas essas questões ficam para a pesquisa empírica e para a prática política.

\section{À GUISA DE CONCLUSÃO-sociologia jurídica clássica e o direito brasileiro contemporâneo}

O direito será sempre uma área de interesse da sociologia. Por isso, faz parte da análise já dos fundadores da sociologia. Compreender a influ- ência dos textos legais, de sua interpretação, das decisões legais na forma como atuam e pensam o mundo os atores sociais, como se estruturam as relações em uma dada sociedade, e como se colocam as desigualdades das classes sociais em meio ao discurso jurídico, entre outras preocupações, relacionando o direito na sociedade a partir de uma visão externa, é função da qual os sociólogos não podem fugir.

As abordagens clássicas não pedem reformulação; pedem continuidades. Tentamos, aqui, apontar como cada um dos clássicos maiores pensou essa temática e levantar questões que não ficaram claras, não por inconsistência do trabalho dos autores, mas muito mais porque algumas questões somente a pesquisa empírica poderá resolver.

Antes de retomar as contribuições clássicas, gostaríamos de pensar como essas teorias podem ser utilizadas para elucidar as práticas jurídicas brasileiras. A teoria social brasileira (DaMatta, 1997; Holanda, 1997; Neder, 1995) tem repetidamente apontado que a construção legislativa nacional tem feito poucos esforços para ser reflexo do corpo social, como assinalaria Durkheim. Antes, trata-se de uma tentativa de controle sobre esse corpo, num esforço modernizante. Assim, tem-se:

[...] um estado legiferante, que busca controlar pela lei a tudo e a todos e um enorme fosso entre leis e práticas, com o descompasso entre leis moderníssimas, porém, aplicadas desigualmente para desiguais (Vargas, 2011, p. 244).

Em oposição à common law britânica, o país adota uma tradição de lei civil, formando um direito extremamente formal, bem formulado em suas leis, que busca abranger o máximo de detalhes concernentes à realidade social, mas pouco relacionado com as práticas cotidianas da população. Como os clássicos da sociologia ajudariam a explicar essa realidade?

A abordagem weberiana utiliza-se do processo de racionalização em todas as esferas da vida social do Estado moderno. O Estado moderno, o direito e os fenômenos sociais oriundos dessa relação - ordem, processo de mudança social, burocracia, racionalidade e o princípio da ação social - 
são ligados aos aspectos subjetivos e objetivos da realidade social. Mas como poderia se consolidar um estado racional com regras abstratamente perfeitas, porém pouco práticas?

Retornando a Weber, vale lembrar que ele atribui ao direito uma importância fundamental para o Estado moderno, pois define as regras que serão preestabelecidas no campo judiciário. Talvez a maior contribuição da sociologia jurídica de Weber seja a questão da profissionalização do direito. Segundo ele, o direito precisa ser uma instituição que analise as contradições internas da sociedade e crie leis que contemplem os cidadãos, e também que seja capaz de reduzir os conflitos sociais. Nesse sentido, não é difícil ver como uma cisão entre profissionais do direito e o senso comum pode se estabelecer. No entanto, isso compromete diretamente a questão da sensibilidade jurídica da população em geral, ou seja, na definição dos momentos em que a população percebe que um direito foi desrespeitado.

Assim, é no limiar entre consentimento e imposição que a análise weberiana pede maiores continuidades, mas que também é mais esclarecedora quanto ao caso brasileiro. Normas sociais surgem nos processos de socialização entre os indivíduos, que atribuem, na constituição da legislação e na criação de regras de conduta, seus valores culturais, religiosos e políticos. Dessa forma, a formação do contrato social teria como norteador a justiça como base de equilíbrio societal. Nesse sentido, a dominação legítima é atribuída às instituições governamentais e administrativas em relação ao conjunto da sociedade civil. Mas há, em meio a essa dominação racional, um questionamento e uma imposição. A pergunta que fica é se o direito brasileiro sofre - e, se sim, em que medida - de uma crise de legitimidade, uma vez que aparece mais como uma imposição do que como um acordo, ou seja, mais como um ato de poder do que de dominação. As condutas, portanto, poderão ser pouco respeitosas ao direito em si, que terá de se impor por mecanismos de poder. Dessa forma, "manda quem pode, obedece quem tem juízo". A forma como isso reverbera no funci- onamento social talvez seja mais bem compreendida retomando as obras de Durkheim e Marx.

Para Durkheim, o direito é uma instituição social de importância ímpar para o funcionamento e a organização moral da sociedade. A solidariedade social definida pela divisão do trabalho social, a moral que é passada de geração em geração e os valores coletivos formam o direito contratual entre os cidadãos, bem como o reconhecimento de pertença a um mesmo organismo estrutural baseado em direitos e deveres individuais e coletivos.

Caso as instituições primárias, como a família, a escola e a igreja, não cumpram com seu papel de passagem dos valores morais da sociedade para um determinado cidadão, esses valores serão restituídos pelas regras coercitivas emanadas do direito. Em que aspecto da vida social ainda se pode reconhecer uma consciência superior aos indivíduos e o que ainda os une como solidariedade social são questões centrais para se entender o direito a partir da perspectiva de Durkheim. Nesse aspecto, como equacionar toda centralidade da perspectiva contratual com o avanço que teve, na segunda metade do século XX, o direito constitucional e a garantia aos direitos fundamentais? Uma nova perspectiva surge dando primazia às constituições sobre os códigos civis (Bonavides, 2007; Canotilho, 2003).

A defesa da sociedade por parte de Durkheim é, sem dúvida, uma prévia para estabelecer a justiça que está intrínseca nas ações que a sociedade delibera do direito restitutivo frente às ações egoístas de alguns indivíduos na transgressão das leis. O porquê de o direito repressivo se manter tão forte e o porquê de os direitos fundamentais ganharem importância na dogmática jurídica recente, por outro lado, são questões em aberto para se entender como os fatos sociais se impõem aos cidadãos sobre os anseios individuais, em prol da vontade coletiva que é, para ele, a fonte da mais legítima justiça social. Podemos especular que as sociedades modernas esbarraram em alguma desarticulação, tendo início algum tipo de anomia, o que pode estar sendo corrigido através de um direito que defende valores centrais da so- 
ciedade com maior força. É possível, assim, compreender o avanço do direito constitucional e do direito penal, explicado pela mesma força social que busca reafirmar os valores mais fundamentais da sociedade. Essa explicação é especialmente profícua para o caso brasileiro, dada a intenção de transformação social que sempre se refletiu nas ditas "moderníssimas" leis do país.

Mas as contradições do direito contemporâneo podem ser entendidas também sob a perspectiva do conflito de classes de Marx. Para ele, o direito se organiza na sociedade e se institucionaliza no Estado. O conteúdo de classes sociais (ideologia) pertence ao campo superestrutural e tem forte influência da infraestrutura (sistema produtivo) na formação do direito moderno. Assim, o conflito de interesses das classes sociais é o fator fundamental para o seu estabelecimento.

Marx coloca que o direito tem sua ligação direta com a forma como se pensa e se pratica na vida social. Desse modo, o direito burguês está muito mais destinado a separar o homem real do homem político, esvaziando a vida política, tornando o indivíduo egoísta inacessível aos desígnios da coletividade. Assim, a liberdade e a segurança mantêm a relação desigual de propriedade presente na sociedade, que se torna intangível por parte do mundo político. Separaríamos, conforme essa visão, o avanço do direito penal - que apareceria como um avanço da proteção da propriedade privada e da segurança do indivíduo emancipado da política - do avanço do direito constitucional, especialmente nas garantias em termos de direito social que ele promove - nesse caso, como uma resistência das classes exploradas, permitindo alguma redistribuição da produção, embora sem questionar o sistema de maneira global. Dentro da estrutura de uma sociedade de classes na qual o direito tem autonomia, como nas sociedades burguesas, o direito pode ser fonte de resistência, ou meramente um instrumento de reprodução das desigualdades de classe, ou mesmo, conforme sugerimos, ambas as possibilidades podem viáveis simultaneamente. Politicamente, a correlação entre liberdade e participação política permanece em aberto também.
Podemos observar que Marx e Durkheim chegam, por vias conceituais distintas, a um mesmo campo problemático do direito: a liberdade de contrato individual e os interesses da coletividade. Os ângulos de visão são claramente distintos, assim como são as preferências políticas desses autores, mas percebe-se a tentativa de articular, na mesma discussão teórica, a relação entre o funcionamento da sociedade e a participação individual. Com Weber, é possível problematizar também a questão da legitimidade do direito. A tudo isso se soma, no caso brasileiro, uma vontade legislativa de modernização, o que levanta ainda mais questões sobre legitimidade das leis e posicionamento político frente aos embates referentes à conciliação entre liberdades individuais, proteção aos direitos fundamentais e aos projetos e vontades referentes à coletividade.

O que se pode verificar é que o direito e a legislação contemporâneos não têm um único princípio vigente. E o posicionamento frente aos embates, que surgem mediante tantos ângulos possíveis de se olhar o direito moderno, pode se refletir também no trabalho dos operadores do direito. A eles cabe a análise técnica das leis, mas talvez caiba, também, uma compreensão de como todos esses diferentes elementos sociais do mundo jurídico se refletem nas dinâmicas sociais. Uma discussão mais profunda desse assunto escaparia ao escopo deste trabalho. Neste breve artigo, priorizamos a análise dos textos clássicos, deixando de lado, por ora, as continuidades que essas obras receberam dentro da sociologia jurídica. Nosso objetivo, além de demonstrar que a sociologia jurídica tem suas raízes na própria formação da sociologia, foi mostrar como ela pode ser trabalhada nas diferentes matrizes sociológicas que os clássicos maiores apresentam. Dessa forma, ressaltamos também a abertura paradigmática que a disciplina comporta desde seu início.

Recebido para publicação em 28 de outubro de 2011 Aceito em 24 de setembro de 2012 


\section{REFERÊNCIAS}

BAUMAN, Z. Em busca da política. Rio de Janeiro: Zahar, 2000.

BONAVIDES, P. Do estado liberal ao estado social. 8.ed. São Paulo: Malheiros, 2007.

BENDIX, R. Um perfil intelectual. Brasília-DF: UnB, 1986. CANOTILHO, J. J. G. Direito Constitucional e teoria da constituição. 7.ed. Coimbra: Edições Almeida, 2003.

DA MATTA, R. Carnavais, malandros e heróis: para uma sociologia do dilema brasileiro. Rio de Janeiro: Rocco, 1997.

DURKHEIM, É. Lições de sociologia: a moral, o direito e o Estado. São Paulo: EDUSP, 1983.

Da divisão do trabalho social. 2.ed. São Paulo: Martins Fontes, 1995.

As regras do método sociológico. São Paulo: Ed. Martin Claret, 2001.

FREUND, J. Sociologia de Max Weber. 4.ed. Rio de Janeiro: Forense Universitária, 1987.

GOULDNER, A. W. Conflitos na teoria de Weber. In: CAMPOS, Edmundo (Org.). Sociologia da burocracia. Rio de Janeiro: Zahar, 1966. p.45-53

HOLANDA, S. B. Raízes do Brasil. São Paulo: Companhia das Letras, 2007.

LYRA, R. F. O que é Direito. São Paulo: Brasiliense, 2005.

MARX, K. A Questão Judaica. Site da Lusofia/UBI. [Consult. em 28 outubro 2011]. Disponível em: http:// www.lusosofia.net/textos/marx_questao_judaica.pdf. $1989 a$

Manuscritos econômicos filosóficos. Lisboa Edições $70,1989 \mathrm{~b}$
MARX, K.; ENGELS, F. Manifesto do Partido Comunista. 2.ed. Lisboa: Avante, 1997.

$\overline{\text { Martins }}$ Fontes. 2002

A ideologia alemã. 3.ed. São Paulo:

NEDER, G. Discurso jurídico e ordem burguesa no Brasil. Porto Alegre: Sergio Antonio Fabris Ed., 1995

QUINTANEIRO, T. et al. Um toque de clássicos. 2.ed. Belo Horizonte: EDUFMG, 2002.

RUSCHE, G.; KIRCHHEIMER, O. Punição e estrutura social. 2.ed. Rio de Janeiro: Revan, 2004

VARGAS, J. D. Em busca da verdade real: tortura e confissão no Brasil ontem e hoje. Sociologia \& Antropologia Niteroi, v.2, n.3, p.237-265, 2012.

WACQUANT, L. Punir os pobres: a nova gestão da miséria nos Estados Unidos [A onda punitiva]. Rio de Janeiro: Revan/Instituto Carioca de Criminologia, 2007.

WEBER, M. Os fundamentos da organizacão burocrática uma construção do tipo ideal. In: CAMPOS, Edmundo (Org.) Sociologia da burocracia. Rio de Janeiro: Zahar, 1966. p.16-27.

Classe, status e partido. In: VELHO, Otávio G. PALMEIRA Moacir G. S.; BERTELLI, Antônio R. (Org.) Estrutura de classes e estratificação social. 6.ed. Rio de Janeiro: Zahar, 1976. p.61-83.

A política como vocação. In: WEBER, Max; $\overline{\text { GERTH}}$, Hans; MILLS, Whigth. Ensaios de sociologia Rio de Janeiro, Zahar. 1979.

A ética protestante e o espírito do capitalismo. São Paulo: Pioneira: UnB, 1981.

Economia e sociedade: fundamentos da sociologia compreensiva. 4.ed. São Paulo: UnB, 2004. 


\section{MODERN LAW UNDER THE LENS OF THE CLASSICS OF SOCIOLOGY: analysis and questions}

\author{
Amílcar Cardoso Vilaça de Freitas \\ Elizardo Scarpati Costa
}

In this article, we intend to undertake an analysis of modern law, working from three classical, sociological approaches (the Weberian, Durkheimian, and Marxian perspectives) to the field of law. We will seek to specify the different sociological interpretations, discussing them departing from the political and social relations established between civil society, the State and the political ideologies that solidify the current configuration of the law. In this manner, and given that one deals with foundational visions, they interest us as much for what they propose as for what they cannot respond to, claiming a continuity with contemporary, juridical sociology, with a special attention given to the Brazilian case. As such, we intend to demonstrate the paradigmatic place that the sociology of law has possessed since its formation and how the law, as a sociological theme, is present at the foundation of the discipline.

KeY-words: Law, State. Civil society. Conflict.

\section{LE DROIT MODERNE DANS LA PERSPECTIVE DES CLASSIQUES DE LA SOCIOLOGIE: analyses et questionnements}

\author{
Amílcar Cardoso Vilaça de Freitas \\ Elizardo Scarpati Costa
}

Cet article se veut de faire une analyse concernant le droit moderne à partir des trois approches classiques de la sociologie - dans la perspective wébérienne, durkheimienne et marxiste du champ du droit. On essayera de préciser les différentes interprétations sociologiques à partir d'une discussion concernant les relations sociales et politiques établies entre la société civile, l'Etat et les idéologies politiques qui incarnent la configuration actuelle du droit. Etant donné qu'il s'agit de visions fondatrices, nous nous intéressons autant à ce qu'elles ont proposé qu'aux questions auxquelles elles n'ont pas su répondre, en exigeant de la sociologie juridique contemporaine qu'elle continue, avec une attention toute spéciale pour le cas brésilien. Nous avons donc f'intention de démontrer l'ouverture paradigmatique de la sociologie du droit, attribut qu'elle a depuis sa formation, et combien le droit en tant que thème sociologique est présent depuis l'implantation de cette discipline.

Mots-CLÉs: Droit. État. Société civile. Conflit. 